\title{
Absence of Beneficial Effect of Intravenous Metoprolol Given during Angioplasty in Patients with Single-Vessel Coronary Artery Disease
}

Jan Willem de Jong, I' Johannes J.R.M. Bonnier, ${ }^{2}$ Tom Huizer, ${ }^{1}$ Renzo Ciampricotti, ${ }^{2}$ and Jos R.T.C. Roelandt, ${ }^{\prime}$

${ }^{1}$ Thoraxcentre, Erasmus University Rotterdam, Rotterdam and ${ }^{2}$ Department of Cardiology, Catharina Hospital, Eindhoven, The Netherlands

\begin{abstract}
Summary. In a double-blind, randomized, placebo-controlled trial, the possible antiischemic effect of metoprolol during percutaneous transluminal coronary angioplasty was tested. Electrocardiograms, hemodynamics, and metabolism were studied in 27 patients with a stenosis in the left anterior descending coronary artery. Measurements took place before angioplasty, after each of four 1-minute occlusions and 15 minutes after the last balloon deflation. Patients were randomly given placebo or metoprolol $(15 \mathrm{mg}$ as a bolus intravenously, followed by an infusion of $0.04 \mathrm{mg} / \mathrm{kg} / \mathrm{hr}$ ). At the end of the procedure, the rate-pressure product had decreased by $15 \%$ (NS) and $23 \%(\mathrm{p}=0.001)$ in the placebo and metoprolol groups, respectively, mainly due to similar decreases in heart rate. Metoprolol tended to lower chest pain and reduce precordial ST-segment elevation due to angioplasty, but the effects were not statistically significant. Lactate, hypoxanthine, and urate release immediately after deflation was similar in both groups. Metoprolol reduced arterial plasma hypoxanthine throughout the procedure by about $30 \%$ ( $\mathrm{p} \leq$ 0.02 vs. placebo). Thus, intravenous infusion of metoprolol did not significantly attenuate chest pain and ST-segment elevation, and failed to decrease cardiac lactate and oxypurine release. It did, however, reduce arterial hypoxanthine concentrations during angioplasty, possibly indicating that the beta-blocker inhibits extracardiac ATP catabolism.
\end{abstract}

Cardiovasc Drugs Ther 1993;7:677-682

Key Words. coronary angioplasty, coronary artery disease, electrocardiography, hypoxanthine, intravenous metoprolol, lactate, pain, rate-pressure product, urate

$\boldsymbol{B}$ eta-adrenergic blockers are commonly used to treat stable angina and hypertension [1-3]. They relieve the symptoms of unstable angina [4]. Frishman and Chang [5] suggested that beta-blockers reduce coronary thrombosis, myocardial infaretion, and sudden death by attenuating the fracture of vulnerable atherosclerotic plaques, in addition to proven effects on heart rate, blood pressure, myocardial contractility, and ventricular ectopy [6,7]. Moreover they diminish postinfarction mortality, as proven in secondary preventative studies $[2,8]$.
In isolated hearts the nonselective beta-blocker propranolol exerts an energy-sparing effect during ischemia $[9,10]$ and has strong chain-breaking antioxidant properties [11]. Beta-blockers, administered intravenously or intracoronarily, diminish ischemia during acute coronary occlusion in humans $[12,13]$. Bonnier et al. [14] showed that a calcium entry blocker, diltiazem, could reduce oxypurine production from high-energy phosphates, induced by percutaneous transluminal coronary angioplasty (PCTA). Thereby the drug diminished flow through the xanthine oxidoreductase pathway, which could generate free radicals. In the present study, published in $a b-$ stract form [15], we hypothesized that the beta ${ }_{1}$ selective blocker metoprolol could further attenuate ischemic injury during PTCA, e.g., by diminishing ATP breakdown.

\section{Methods}

\section{Study population}

The trial involved 27 patients with one-vessel coronary artery disease undergoing PTCA. All patients had an isolated proximal stenosis in the left anterior descending artery (narrowing $>80 \%$ ), without demonstrable collaterals. Beta-blocker treatment was discontinued $\geq 1$ week before the procedure; other cardioactive drugs were withheld 48 hours before the study. With the exception of heparin, no drugs were given during the investigation before completion of data acquisition. The institutional committee on patient research approved the project. All patients gave

Address for correspondence: Jan Willem de Jong, PhD, FESC Cardiochemical Laboratory/Thoraxcentre, Erasmus University Rotterdam, P.O. Box 1738, 3000 DR Rotterdam, The Netherlands.

Received 3 September 1992, accepted in revised form 12 March 1993 
informed consent before the study; they did not suffer protocol-related complications.

\section{Coronary angioplasty}

The procedure has been described in detail earlier [14]. Briefly, a diagnostic catheter was introduced in the great cardiac vein. A guiding catheter was introduced percutaneously and advanced to the aortic root. The left anterior descending artery was visualized with contrast medium after the first venous and arterial samples were taken. Then PTCA was performed using a standard balloon catheter, with maximal inflation pressures ranging from 6 to $12 \mathrm{~atm}$. For each patient, the dilatations were sustained for 60 seconds, regardless of chest pain; four consecutive dilatations were done, with $\geq 5$ minutes between each inflation, and followed by control coronary angiography. Stenosis diameter was determined independently by three experienced cardiologists, using the digital calliper method. They measured the stenotic segment and compared it with the mean of adjacent normal segments on an end-diastolic frame in at least two different angiographic projections.

\section{Experimental regimen}

The patients were randomly treated with placebo or beta-blocker (double blind). After baseline arterial and venous samples had been taken, three loading doses of $5 \mathrm{mg}(5 \mathrm{ml})$ of a racemic mixture of $\mathrm{S}$ - and R-metoprolol tartrate (Seloken ${ }^{\circledR}$, Astra) or placebo (5 $\mathrm{ml}$ saline) were rapidly injected intravenously at 2minute intervals. Then the first dilatation took place. The bolus injections were followed by a continuous infusion of metoprolol $0.04 \mathrm{mg} / \mathrm{kg} / \mathrm{hr}$ (or placebo) after the second balloon deflation. (For continuous use the drug was diluted with saline to $0.1 \mathrm{mg} / \mathrm{ml}$.) Plasma metoprolol was determined gas chromatographically with electron capture detection [16].

\section{Sampling}

Great cardiac venous and femoral arterial blood samples, taken before, immediately after each deflation, and 15 minutes after the procedure, were processed as previously described [14].

\section{Lactate and purine analysis}

In the deproteinized samples, lactate was determined enzymatically [17]. In addition, the ATP-catabolites hypoxanthine and urate were assayed by highperformance liquid chromatography [18], as modified by Huizer et al. [19]. Hypoxanthine and urate were detected at 254 and $290 \mathrm{~nm}$, respectively.

\section{Electrocardiograms}

These were monitored from the precordial leads $V_{2}$, $\mathrm{V}_{4}$, and $\mathrm{V}_{6}$, and the intracoronary lead, and analyzed as described before [14].

\section{Pain}

At the end of each inflation, patient's chest discomfort was scored with Borg's new pain scale [20].

\section{Statistical analysis}

The statistical package for social science (SPSS-X) was used for data analysis. Adequacy of metoprolol dosing was evaluated by comparing the post-PTCA heart-rate and double-product values with baseline data (Students' t-test). ECG variables and arteriovenous differences were expressed as changes from baseline before being subject to multivariate analysis. Analysis of variance with repeated measurements was used, with treatment and time as variables. Student's t-test was used for the between-group analysis, except for the comparison of the chest-discomfort rating scale (Mann-Whitney two-sample test). Unless otherwise stated, results are given as mean \pm standard error. $p<0.05$ was considered significant.

\section{Results}

\section{Clinical characteristics}

The study population was relatively homogeneous; for example, age and severity of the stenosis in the left anterior descending artery (Table 1), and ejection fraction of the left ventricle (not shown), in the two groups were similar. The disease of all patients was classified as Grade III of the Canadian Cardiovascular Society. They experienced angina pectoris only during exercise and received antianginal therapy.

Inflation time, inflation pressure, and pain symptoms during the four consecutive inflations were similar in the metoprolol group (average 59.8 seconds, 11 out of 12 patients with pain) and the placebo group (average 60.2 seconds, all 15 patients with pain). Due to coronary angioplasty, the cross-sectional area of the stenosis decreased by about $85 \%$ in both groups (Table 1). No changes in nonstenotic coronary artery lumen diameter were observed. The baseline values of plasma lactate, hypoxanthine, and urate were similar for both groups.

\section{Hemodynamics}

Systolic and diastolic blood pressure did not change significantly throughout the procedure (Figure 1). In the placebo group, heart rate decreased $15 \% 15$ minutes after the last deflation ( $p=0.007$ vs. baseline); in the metoprolol group, heart rate dropped by $23 \%$ ( $p<0.001$ vs. baseline, $p=0.03$ vs. placebo). The rate-pressure product fell significantly only in the latter (by 23\%, $\mathrm{p}=0.001$ ). Metoprolol did not influence this variable significantly in comparison with placebo (Figure 1).

\section{Electrocardiographic measurements}

Precordial ST-segment changes (as the mean of the anterior wall leads $V_{2}, V_{4}$, and $V_{6}$ ) tended to be 
Table 1. Clinical characteristics of the study groups

\begin{tabular}{lcc}
\hline & $\begin{array}{l}\text { Placebo } \\
\text { group } \\
(\mathrm{n}=15)\end{array}$ & $\begin{array}{l}\text { Metoprolol } \\
\text { Vroup } \\
(\mathrm{n}=12)\end{array}$ \\
\hline Age (yrs) & $59 \pm 2$ & $57 \pm 2$ \\
$\quad$ Average $\pm \mathrm{SE}$ & $46-75$ & $42-72$ \\
$\quad$ Range & $12 / 3$ & $10 / 2$ \\
Sex: M/F & 1 & 1 \\
Essential hypertension & 0 & 1 \\
Hyperlipidemia & 6 & 8 \\
Smokers (presently) & 0 & 2 \\
Irregular heart rhythm & 1 & 0 \\
Diabetes mellitus & & $92.5 \pm 1.3$ \\
Diameter of stenosis $(\%)$ & $93.0 \pm 0.8$ & $15.3 \pm 1.3$ \\
$\quad$ Before angioplasty & $15.6 \pm 0.7$ & \\
$\quad$ After angioplasty & & \\
\hline
\end{tabular}

None of the differences reached significance at $p<0.05$.
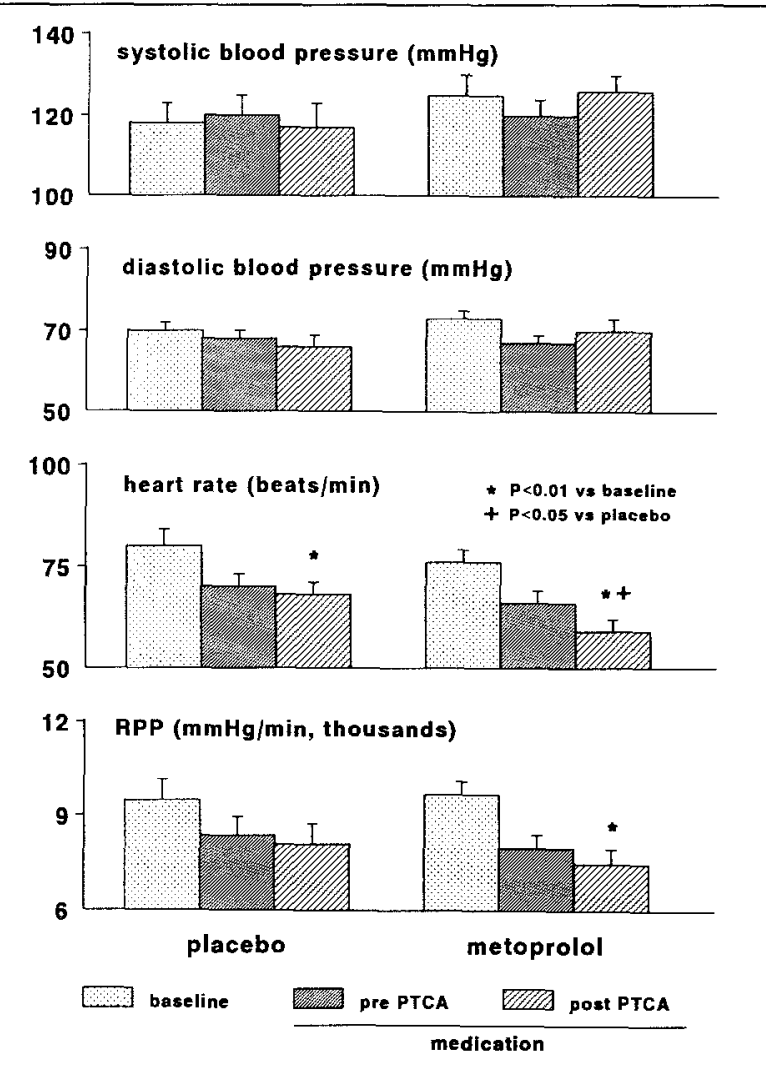

Fig. 1. Hemodynamics before medication, after the bolus injections, and 15 minutes after the last deflation. Metoprolol treatment ( $n=12$ ) induced a larger decrease in heart rate than placebo treatment $(n=15)$; however, the drop in rate-pressure product $(R P P)$ did not differ significantly between the groups.
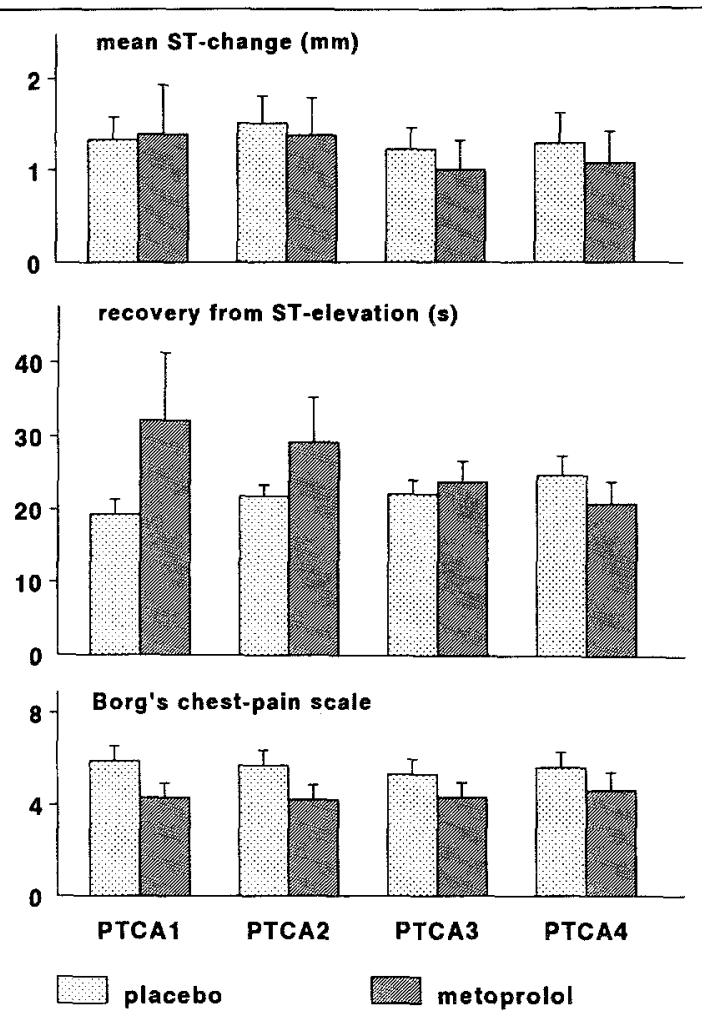

Fig. 2. Effect of metoprolol on precordial ST-segment changes, recovery of ST elevation, and chest pain during angioplasty. The pain scale is in arbitrary units: $0=$ no pain; $10=$ extremely strong pain. $n=9-15$.

smaller in the metoprolol group, but no statistically significant differences were found between the treatments (Figure 2). The absolute intracoronary and peak ST-segment changes, as well as the time to onset of the ST changes, showed similar results. The time to recovery of ST-elevation-initially somewhat higher in the metoprolol group-also tended to decrease under the influence of the drug, and to increase in the placebo group but the p value was 0.060 (NS, Figure 2).

\section{Chest pain}

The groups did not differ statistically with regard to pain experienced during balloon inflation. However, the metoprolol group consistently scored less pain than the placebo group (Figure 2).

\section{Lactate metabolism}

The arterial lactate concentrations were lower in the metoprolol group than in the placebo group, but the drug did not significantly affect them $(\mathrm{p}=0.059$, Figure 3). The same was true for the great cardiac venous lactate concentrations after angioplasty, which doubled in both groups. Also the arteriovenous difference in lactate was comparable between the groups. 


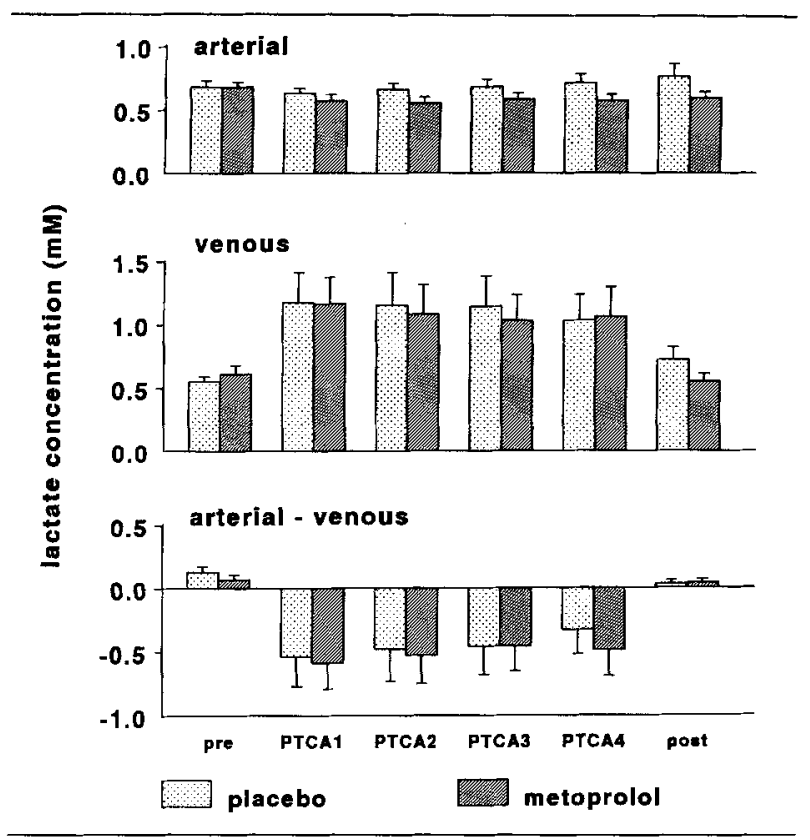

Fig. 3. Effect of metoprolol on lactate metabolism of the heart. Drug treatment started after collection of baseline data. Immediately after angioplasty, lactate production was noted, as the great cardiac venous concentrations exceeded the arterial ones. No significant effects of metoprolol treatment were found. $n=12-15$.

\section{Hypoxanthine metabolism}

The arterial and venous concentrations of hypoxanthine are given in Figure 4 . In both groups, the arterial concentrations fell after the first deflation and remained low. After each dilatation, the arterial hypoxanthine concentrations in the metoprolol group were about 30\% lower than in the placebo group ( $p \leq 0.02)$. The great cardiac venous levels remained more or less constant during the study. The groups showed no significant differences in venous hypoxanthine concentrations or hypoxanthine production due to PTCA (Figure 4).

\section{Urate release}

Metoprolol had no significant effect on the arterial and venous urate concentrations, nor on urate production by the heart. The initial arterial and venous values in the metoprolol group were $252 \pm 20 \mu \mathrm{M}$ and $250 \pm$ $20 \mu \mathrm{M}$, respectively; in the placebo group, they were $244 \pm 9 \mu \mathrm{M}$ and $243 \pm 9 \mu \mathrm{M}$, respectively. The concentrations varied less than 10\% throughout the procedure (data not shown). Thirty percent of the hearts produced minor amounts of urate before PTCA, in contrast to the majority of hearts (usually $70 \%$ ) after each deflation.

\section{Metoprolol levels}

The plasma concentrations of metoprolol, measured 5 minutes after the last deflation, varied relatively little $(164 \pm 18 \mathrm{nM})$.

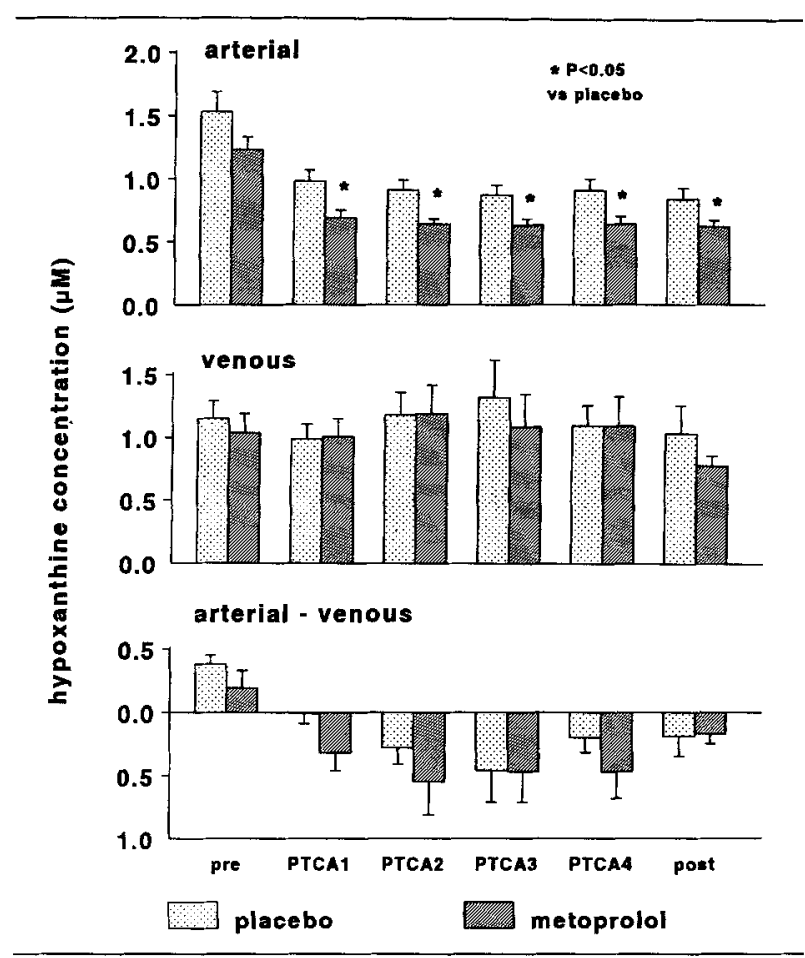

Fig. 4. Effect of metoprolol on arterial and great cardiac venous hypoxanthine concentrations. Treatment with beta-blocker lowered the arterial concentration during the procedure significantly. However, cardiac hypoxanthine production due to angioplasty was not significantly influenced. $n=12-15$.

\section{Discussion}

\section{Metoprolol effects}

We were unable to confirm our hypothesis that metoprolol could attenuate signs of ischemia during PTCA. Intravenous infusion of metoprolol tended to attenuate chest pain and ST-segment elevation, but failed to affect cardiac lactate and oxypurine release. It did, however, reduce significantly the arterial hypoxanthine concentrations during angioplasty, possibly indicating that the beta-blocker inhibits extracardiac ATP catabolism.

\section{Metoprolol dosing}

The plasma levels measured at the end of the procedure were within the therapeutic range for metoprolol [21]. We observed the expected drop in heart rate and double product (Figure 1), indicating that the drug partially suppressed the beta-adrenergic system of the patients. The time effects found with some variables, e.g., recovery from ST-segment elevation, are perhaps due to metoprolol accumulation in cardiac tissue [22].

\section{ECG changes and chest pain}

The leads used included those optimal for monitoring ischemia of the area perfused by the left anterior de- 
scending coronary artery [23]. We did not detect a statistically significant effect of metoprolol treatment on ST-segment changes or chest pain during coronary angioplasty (Figure 2). However, the ST-segment changes and chest pain tended to be smaller in the metoprolol group. Labovitz et al. [24] recently observed some decrease of duration and extent of maximal ST-segment elevation during angioplasty by ultrashort-lasting beta-adrenergic blockade. Metoprolol administration is highly effective in reducing ambulatory ischemia, as evidenced by ST depression during daily life [25].

\section{Lactate production}

Metoprolol was without effect on cardiac lactate metabolism (Figure 3). The drug tended to reduce the arterial lactate levels, which is in line with the findings in healthy subjects [26] and with the reduction of arterial hypoxanthine (vide infra). The decrease in arterial lactate is possibly due to impaired translocation of lactate from the sites of production [27].

\section{Oxypurine metabolism}

After ischemia, the human heart releases hypoxanthine due to ATP catabolism [14,18,28-30]. In contrast to earlier work $[14,30]$, coronary occlusion did not influence venous hypoxanthine. Still the arteriovenous difference became negative, because the arterial levels fell. The difference from earlier studies is the somewhat shorter balloon inflation time, which could explain the discrepancy.

Metoprolol reduced the arterial hypoxanthine concentrations during the procedure (Figure 4). This could indicate that the drug attenuates extracardiac ATP breakdown. In fact, there is some in vitro evidence that beta-blockade depresses ATPase activity [31]. The clinical significance of the reduction in arterial hypoxanthine remains to be elucidated. It would be of interest to know whether metoprolol also modulates the concentration of the hypoxanthine precursor adenosine, a regulator of many physiological processes.

The appearance of urate indicates that human heart contains some xanthine oxidoreductase activity [29]. On the other hand, perfusion of explanted human hearts with hypoxanthine gives rise to negligible urate production [32]. We still have to learn whether human heart contains the desulpho form of xanthine oxidase, which generates free radicals but not urate [33].

\section{Conclusions}

Intravenous infusion of metoprolol did not significantly attenuate PCTA-induced signs of ischemia. Therefore this form of therapy should not be considered appropriate for all patients undergoing PTCA.

\section{Acknowledgments}

We thank Berry van Gelder, RN, and the staff of the catheterization laboratory for their patient collaboration. We are grateful to Heleen van Loon, BSc, for analytical expertise; to Lars Johansson, $\mathrm{PhD}$, for the determination of the metoprolol levels; to Bert Meems, MSc, and Jan Tijssen, PhD, for statistical assistance; and to Carina Poleon for secretarial help. We also thank Astra (The Netherlands) for support of this study.

\section{References}

1. Boberg J, Larsen FF, Pehrsson SK. The effects of beta blockade with (epanolol) and without (atenolol) intrinsie sympathomimetic activity in stable angina pectoris. The Visacor Study Group. Clin Cardiol 1992;15:591-595.

2. Hansson L. Review of state-of-the-art beta-blocker therapy. Am J Cardiol 1991;67:43B-46B.

3. Magnani B, Rapezzi C, Galie N, Ortolani P. Use of multipleaction agents on the heart: Pathophysiological and therapeutic considerations. J Cardiovasc Pharmacol 1992;19(Suppl 1):S44-S49.

4. The HINT Research Group. Early treatment of unstable angina in coronary care unit: A randomised, double blind, placebo controlled comparison of recurrent ischaemia in patients treated with nifedipine or metoprolol or both. $\mathrm{Br}$ Heart I 1986;56:400-413.

5. Frishman WH, Chang CM. Beta-adrenergic blockade in the prevention of myocardial infaretion: A new theory. J Hypertens 1991;9(Suppl):S31-S34.

6. Wikstrand, J, Berglund G, Tuomilehto J. Beta-blockade in the primary prevention of coronary heart disease in hypertensive patients. Review of present evident. Circulation 1991;84(Suppl 6):VI93-VI100.

7. Olsson G, Tuomilehto J, Berglung G, et al. Primary prevention of sudden cardiovascular death in hypertensive patients. Mortality results from the MAPHY study. Am $J$ Hypertens 1991;4:151-158.

8. Olsson G, Wikstrand J, Warnold, I et al. Metoprolol-induced reduction in postinfarction mortality: Pooled results from five double-blind randomized trials. Eur Heart $J$ 1992; 13:28-32.

9. Harmsen E, De Tombe PP, De Jong JW. Synergistic effect of nifedipine and propranolol on adenosine (catabolite) release from ischemic rat heart. Eur $J$ Pharmacol 1983; 90:401-409.

10. Wangler RD, DeWitt DF, Sparks HV, Jr. Effect of betaadrenergic blockade on nucleoside release from the hypoperfused isolated heart. Am J Physiol 1984;247:H330-H336.

11. Mark IT, Weglicki WB. Protection by beta-blocking agents against free radical-mediated sarcolemmal lipid peroxidation. Circ Res 1988;63:262-266.

12. Feldman RL, MacDonald RG, Hill JA, et al. Effect of propranolol on myocardial ischemia oceurring during acute coronary occlusion. Circulation 1986;73:727-733.

13. Zalewski A, Goldberg S, Dervan JP, Slysh S, Maroko PR. Myocardial protection during transient coronary occlusion in man: Beneficial effects of regional $\beta$-adrenergic blockade. Circulation 1986;73:734-739.

14. Bonnier JJRM, Huizer T, Troquay R, et al. Myocardial protection by intravenous diltiazem during angioplasty of single-vessel coronary artery disease. Am J Cardiol 1990; $66: 145-150$. 
15. Bonnier JJRM, De Jong JW, Huizer T, et al. Effect of intravenous metoprolol given during coronary angioplasty (PTCA). Eur Heart $J$ 1991;12(Abstr Suppl): 91.

16. Ervik M, Kylberg-Hanssen K, Johansson L. Determination of metoprolol in plasma and urine using high-resolution gas chromatography and electron capture detection. $J$ Chromatogr 1986;381:168-174.

17. Gutmann I, Wahlefeld AW. L-(+)-lactate determination with lactate dehydrogenase and NAD. In: Bergmeyer H-U, ed. Methods of Enzymatic Analysis, Vol 3, 2nd ed. Weinheim: Verlag Chemie, 1974;1464-1468.

18. Harmsen E, De Jong JW, Serruys PW. Hypoxanthine production by ischemic heart demonstrated by high pressure liquid chromatography of blood purine nucleosides and oxypurines. Clin Chim Acta 1981;115:73-84.

19. Huizer T, De Jong JW, Achterberg PW. Protection by bepridil against myocardial ATP-catabolism is probably due to negative inotrophy. $J$ Cardiovasc Pharmacol 1987;10:55-61.

20. Borg G, Holmgren A, Lindblad I. Quantitative evaluation of chest pain. Acta Med Scand 1981;Suppl 644:43-45.

21. Sandberg A, Abrahamsson B, Regårdh C-G, et al. Pharmacokinetic and biopharmaceutic aspects of once daily treatment with metoprolol CR/ZOK: A review article. $J$ Clin Pharmacol 1990;30:S2-S16.

22. Ryden L, Tadokoro H, Sjoquist P-O, et al. Pronounced accumulation of metoprolol in ischemic myocardium after coronary venous retroinfusion. J Cardiovasc Pharmacol 1990;15:22-28.

23. Bush H, Ferguson III JJ, Angelini P, Willerson JT. Twelvelead electrocardiography evaluation of ischemia during percutaneous transluminal coronary angioplasty and its correlation with acute reocclusion. Am Heart $J$ 1991;121: 1591-1599.

24. Labovitz AJ, Barth C, Castello R, et al. Attenuation of myocardial ischemia during coronary occlusion by ultrashort-acting beta adrenergic blockade. Am Heart $J$ 1991; 121:1347-1352.

25. Ardissino D, Savonitto S, Egstrup K, et al. Transient myocardial ischemia during daily life in rest and exertional angina pectoris and comparison of effectiveness of metoprolol versus nifedipine. Am J Cardiol 1991;67:946-952.

26. Van Baak MA. Beta-adrenoceptor blockade and exercise. Sports Med 1988;5:209-225.

27. Frisk-Holmberg M, Jorfeldt L, Juhlin-Dannfelt A. Metabolic effects in muscle during antihypertensive therapy with beta 1- and beta 1/beta 2-ađrenoceptor blockers. Clin Phar macol Ther 1981;30:611-618.

28. Remme WJ, Van den Berg R, Mantel M, et al. Temporal relation of changes in regional coronary flow and myocardial lactate and nucleoside metabolism during pacing induced ischemia. Am J Cardiol 1986;58:1188-1194.

29. Huizer T, De Jong JW, Nelson JA, et al. Urate production by human heart. J Mol Cell Cardiol 1989;21:691-695.

30. Serruys PW, Suryapranata H, Piscione F, et al. Myocardial release of hypoxanthine and lactate during percutaneous transluminal coronary angioplasty. Am J Cardiol 1989; 63:45E-51E.

31. Dzurba A, Ziegelhöffer Am, Schmidtova L, et al. Exaprolol as a modulator of heart sarcolemmal $\left(\mathrm{Na}^{+}+\mathrm{K}^{+}\right)$-ATPase. Evidence for interaction with an essential sulfhydryl group in the catalytic centre of the enzyme. Gen Physiol Biophys $1985 ; 4: 257-264$.

32. De Jong JW, Van der Meer P, Nieukoop AS, et al. Xanthine oxidoreductase activity in perfused hearts of various species, including humans. Circ Res 1990;67:770-773.

33. S Abadeh, Killacky J, Benboubetra M, Harrison R. Purification and partial characterization of xanthine oxidase from human milk. Biochim Biophys Acta 1992;1117:25-32. 